\title{
Cross-linking of the DNA repair protein O6-alkylguanine DNA alkyltransferase to DNA in the presence of antitumor nitrogen mustards
}

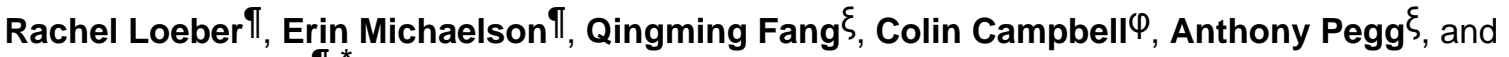 \\ Natalia Tretyakova ${ }^{,}{ }^{*}$ \\ IDepartment of Medicinal Chemistry and Cancer Center, University of Minnesota, Minneapolis, MN \\ 55455
}

फDepartment of Pharmacology, University of Minnesota, Minneapolis, MN 55455

¿Department of Cellular and Molecular Physiology, Pennsylvania State University College of Medicine, Hershey, PA 17033

\begin{abstract}
The antitumor activity of chemotherapeutic nitrogen mustards including chlorambucil, cyclophosphamide, and melphalan, is commonly attributed to their ability to induce DNA-DNA cross-links by consecutive alkylation of two nucleophilic sites within the DNA duplex. DNA-protein cross-linking by nitrogen mustards is not well characterized, probably because of its inherent complexity and the insufficient sensitivity of previous methodologies. If formed, DNA-protein conjugates are likely to contribute to both target and off-target cytotoxicity of nitrogen mustard drugs. Here we show that the DNA repair protein, $O^{6}$-alkylguanine DNA alkyltransferase (AGT), can be readily cross-linked to DNA in the presence of nitrogen mustards. Both chlorambucil and mechlorethamine induced the formation of covalent conjugates between ${ }^{32} \mathrm{P}$-labeled double-stranded oligodeoxynucleotides and recombinant human AGT protein, which were detected by SDS-PAGE. Capillary HPLC-electrospray ionization mass spectrometry (ESI-MS) analysis of AGT that had been treated with guanine half mustards of chlorambucil or mechlorethamine revealed the ability of the protein to form either one or two cross-links to guanine. C145A AGT - a variant containing a single point mutation in the protein's active site - was found capable of forming a single guanine conjugate, while cross-linking was virtually abolished upon treatment of the C145A/C150S AGT double mutant with the guanine half mustards. HPLC-ESI ${ }^{+}$-MS/MS sequencing of the tryptic peptides obtained from the wild type AGT protein that had been treated with nitrogen mustards in the presence of DNA confirmed that the cross-linking took place between the N7 position of guanine in DNA and two active site residues within the AGT protein (Cys ${ }^{145}$ and Cys ${ }^{150}$ ). The exact chemical structures of AGT-DNA cross-links induced by chlorambucil and mechlorethamine were identified as $N-(2-[S$ cysteinyl] ethyl)- $N$-(2-[guan-7-yl]ethyl)-p-aminophenylbuyric acid and $N$-(2-[Scysteinyl]ethyl)- $N$ (2-[guan-7-yl]ethyl)methylamine, respectively, based upon HPLC-MS/MS analysis of protein hydrolysates in parallel with the corresponding amino acid conjugates prepared synthetically. Mechlorethamine-induced AGT-DNA conjugates were isolated from protein extracts of AGT-
\end{abstract}

*To whom correspondence should be addressed: University of Minnesota Cancer Center, 420 Delaware St SE - MMC 806, Minneapolis, MN 55455, USA. ph: 612-626-3432 fax: 612-626-5135 trety001@umn.edu.

Supporting Information Available: Synthetic procedures for the preparation of the guanine half mustards and amino acid-guanine conjugates of chlorambucil and mechlorethamine, SDS-PAGE analysis of nitrogen mustard-induced histone H4-DNA cross-links, MS spectra of histone $\mathrm{H} 4$ following exposure to guanine half mustards, MS/MS spectra of AGT tryptic peptides containing nitrogen mustardinduced lesions, and amino acid sequences of human AGT variants and bovine histone H4 can be found in the Supporting Information. This material is available free of charge via the Internet at http://pubs.acs.org. 
expressing $\mathrm{CHO}$ cells, but not control cells, demonstrating that nitrogen mustards can cross-link the AGT protein to DNA in the presence of other nuclear proteins. Because AGT is overexpressed in many tumor types, further investigations of potential role of AGT-DNA cross-linking in the antitumor and mutagenic activity of antitumor nitrogen mustards is warranted.

\section{Introduction}

Nitrogen mustard drugs are broadly used in the clinic against a variety of neoplastic conditions, including lymphoma, leukemia, multiple myeloma, and ovarian carcinoma. These drugs can react with nucleophilic sites within DNA or proteins, giving rise to DNA-DNA and DNAprotein cross-links. DNA-DNA cross-linking by nitrogen mustards is well characterized and is thought to be largely responsible for their cytotoxic effects $(1 ; 2)$. In contrast, DNA-protein cross-linking by nitrogen mustards is not well studied, despite their potential role in cytotoxicity and/or mutagenicity. Many other bis-electrophiles including 1,2-dibromoethane (DBE), 1,2,3,4-diepoxybutane (DEB), platinum drugs, and dialhehydes, induce covalent cross-links between DNA and DNA binding proteins (histones, DNA repair proteins, and transcription factors) $(3 ; 4)$, raising the prospect that similar lesions may result from nitrogen mustard chemotherapy. If not repaired, DNA-protein cross-links can cause the blockage of the replication fork, accumulation of mutations, and the induction of pro-apoptotic processes (4).

One human protein that is readily cross-linked to DNA in the presence of bis-electrophiles is the DNA repair protein $O^{6}$-alkylguanine DNA alkyltransferase (AGT) $(5 ; 6)$. The expression of human AGT in bacteria enhances the cytotoxic and mutagenic effects of DBE and DEB (5), presumably due to the formation of covalent AGT-DNA cross-links $(5 ; 6)$. The normal physiological function of AGT protein is to transfer the $O^{6}$-alkyl group from promutagenic $O^{6}$-alkylguanine lesions in DNA to an active site cysteine (Cys ${ }^{145}$ in the human protein), restoring normal guanine and preventing mutagenesis (7). Our present study employed a combination of mass spectrometry, site specific mutagenesis, and affinity capture techniques to demonstrate that antitumor nitrogen mustards can form covalent cross-links between the active site residues of AGT and DNA. We further show that this cross-linking reaction is not inhibited by free cysteine and takes place in the presence of other cellular proteins.

\section{Materials and Methods}

\section{Chemicals and Reagents}

Mechlorethamine hydrochloride and chlorambucil were purchased from Sigma-Aldrich (Milwaukee, WI). L-Cysteine and Boc-L-Cys-OH were obtained from Fluka (Buchs, Switzerland), and Boc-Lys-OMe was purchased from Bachem (King of Prussia, PA). 2'Deoxyguanosine was obtained from TCI America (Portland, OR). Guanine half mustards of chlorambucil and mechlorethamine, $N$-(2-chloroethyl)- $N$-[2-(guan-7-yl)ethyl]- $p$ aminophenylbutyric acid (N7G-PBA-Cl) and $N$-(2-chloroethyl)- $N$-[2-(guan-7-yl)ethyl] methylamine (N7G-EMA-Cl), were prepared by reacting 2'-deoxyguanosine with the corresponding mustards as described in the Supporting Information (S-1). Amino acid-guanine conjugates of chlorambucil and mechlorethamine, $N$-(2-[S-cysteinyl]ethyl)- $N$-(2-[guan-7-yl] ethyl)-p-aminophenylbuyric acid (Cys-N7G-PBA), $N$-[2-[S-cysteinyl]ethyl]- $N$-[2-(guan-7-yl) ethyl]methylamine (Cys-N7G-EMA), and $N$-[2-[N-(lysyl)ethyl]- $N$-[2-(guan-7-yl)ethyl] methylamine (Lys-N7G-EMA), were prepared by reacting the corresponding protected amino acids with N7G-EMA-Cl or N7G-PBA-Cl, followed by deprotection and HPLC purification (Supporting Information S-1). $\left[\gamma^{32} \mathrm{P}\right]-\mathrm{ATP}$ was from Perkin-Elmer (Boston, MA), and T4 polynucleotide kinase was obtained from New England Biolabs (Beverly, MA). Trypsin, carboxypeptidase $\mathrm{Y}$, and proteinase $\mathrm{K}$ were purchased from Worthington Biochemical Corporation (Lakewood, NJ). Synthetic peptide GNPVPILIPCHR (which corresponds to 
positions 136-147 of AGT) and all synthetic DNA oligodeoxynucleotides were prepared at the University of Minnesota Microchemical Facility (Minneapolis, MN). Bovine histone H4 was purchased from Roche Applied Science (Indianapolis, IN). Human recombinant AGT proteins (C-terminal histidine-tagged wild type and N-terminal histidine-tagged C145A and $\mathrm{C} 145 \mathrm{~A} / \mathrm{C} 150 \mathrm{~S}$ mutants) were prepared as described previously (8;9). Mouse monoclonal antibody specific for AGT (MGMT, clone MT3.1) was purchased from Millipore (Temecula, $\mathrm{CA}$ ), and the alkaline phosphatase-conjugated anti-mouse $\operatorname{IgG}$ secondary antibody was obtained from Sigma (St. Louis, MO). Streptavidin sepharose high performance beads were purchased from GE Healthcare (Piscataway, NJ), and proteomics grade trypsin (Trypsin Gold) was obtained from Promega (Madison, WI).

\section{Denaturing PAGE of Nitrogen Mustard-Induced DNA-Protein Cross-Links}

DNA 18-mer, 5'-GGAGCTGGTGGCGTAGGC-3' (200 pmol), was 5'-end labeled with ${ }^{32} \mathrm{P}$ in the presence of $\left[\gamma^{32} \mathrm{P}\right] \mathrm{ATP}$ and T4 polynucleotide kinase, purified by $12 \%$ denaturing PAGE, and desalted by SPE. The ${ }^{32} \mathrm{P}$-labeled duplex $(0.93 \mathrm{nmol})$ was incubated with human recombinant AGT or Histone $\mathrm{H} 4(2.0 \mu \mathrm{g})$ in the presence of 50-200 molar equivalents of mechlorethamine or chlorambucil $\left(4.7,9.3\right.$, and $18.6 \mathrm{nmol}$ respectively) for $3 \mathrm{~h}$ at $37^{\circ} \mathrm{C}$. The reaction mixtures were separated by $12 \%$ SDS-PAGE, and the radiolabeled products were visualized using a Bio-Rad Molecular Imager FX. Nitrogen mustard-induced DNA-protein cross-linking was quantified by volume analysis employing Bio-Rad Quantity One Software, with cross-linking efficiency determined by the relative intensity of the reduced-mobility band versus the band corresponding to single-stranded DNA.

\section{Reactions of Synthetic Peptide GNPVPILIPCHR with Guanine Half Mustards}

Synthetic peptide GNPVPILIPCHR (76.1 nmol), representing residues 136-147 of WT AGT protein, was reacted with 5 equivalents of N7G-PBA-Cl or N7G-EMA-Cl $(380.5 \mathrm{nmol})$ in 10 $\mathrm{mM}$ TRIS- $\mathrm{HCl}$ buffer, $\mathrm{pH} 7.2$, at $37^{\circ} \mathrm{C}$ for $2 \mathrm{~h}$, followed by HPLC-ESI ${ }^{+}$-MS/MS analysis as described below.

\section{Reaction of Guanine Half Mustards with Recombinant AGT and Histone Proteins}

Purified recombinant wild type AGT, its variants (C145A AGT and C145A/C150S AGT), or histone $\mathrm{H} 4(3.4 \mathrm{nmol})$ were incubated with N7G-PBA-Cl or N7G-EMA-Cl $(85.8 \mathrm{nmol})$ in 10 $\mathrm{mM}$ TRIS-HCl buffer ( $\mathrm{pH} 7.2)$ for $3 \mathrm{~h}$ at $37^{\circ} \mathrm{C}$. In competition experiments, 100 and 500 molar equivalents L-cysteine $(0.34$ and $1.7 \mu \mathrm{mol}$ respectively) was added. The alkylated proteins were subjected to HPLC-ESI ${ }^{+}$-MS analysis.

Tryptic digestion of alkylated proteins-Control or alkylated protein $(\sim 70 \mu \mathrm{g})$ was digested with trypsin $(7.0 \mu \mathrm{g})$ in $100 \mathrm{mM}$ ammonium bicarbonate buffer $(\mathrm{pH} 7.9)$ for $24 \mathrm{~h}$ at $37^{\circ} \mathrm{C}$. Samples were dried, re-dissolved in $50 \mu \mathrm{L}$ of $0.5 \%$ formic acid $/ 0.01 \% \mathrm{TFA}$, and subjected to analysis by HPLC-ESI ${ }^{+}$-MS/MS.

Total digestion of alkylated proteins to amino acids-Tryptic peptides (from $\sim 50 \mu \mathrm{g}$ protein) were filtered through Microcon YM-10 membrane filters to remove trypsin. Carboxypeptidase $\mathrm{Y}(1.0 \mu \mathrm{g})$ and proteinase $\mathrm{K}(1.0 \mu \mathrm{g})$ were added to the filtrate, and proteolysis proceeded at room temperature for $24 \mathrm{~h}$. Samples were dried and reconstituted in $15 \mathrm{mM}$ ammonium acetate buffer (pH 5.0) prior to HPLC-ESI ${ }^{+}$-MS/MS analysis.

\section{AGT Cross-Linking to Double-Stranded Oligodeoxynucleotides in the Presence of Chlorambucil and Mechlorethamine}

Synthetic DNA 18-mer duplexes (5'-GGAGCTGGTGGCGTAGGC-3', + strand) were incubated with recombinant AGT $(45 \mu \mathrm{g}, 2.1 \mathrm{nmol})$ in the presence of mechlorethamine or 
chlorambucil (200 nmol) in $10 \mathrm{mM}$ Tris- $\mathrm{HCl}$ buffer $(\mathrm{pH} 7.2)$ for $3 \mathrm{~h}$ at $37^{\circ} \mathrm{C}$. Samples were heated at $70^{\circ} \mathrm{C}$ for $1 \mathrm{~h}$ to release $\mathrm{N} 7$-alkylated guanines, followed by tryptic digestion as described for half mustard-treated proteins and HPLC-ESI ${ }^{+}$-MS/MS analysis.

\section{Mass Spectrometry}

HPLC-ESI ${ }^{+}$-MS analysis of alkylated proteins was performed using an Agilent 1100 capillary HPLC-ion trap MS system operated in the $\mathrm{ESI}^{+}$mode. Spectra were obtained by performing full scan MS within the $m / z$ range of 100-1500. Separation was achieved with a Zorbax 300 SB-C3 column $(150 \mathrm{~mm} \times 0.5 \mathrm{~mm}, 5 \mathrm{um})$ eluted at a flow rate of $15 \mu \mathrm{L} / \mathrm{min}$. The column was eluted with a gradient of $0.05 \%$ TFA in water (A) and $0.05 \%$ TFA in acetonitrile (B). Solvent composition was held at $30 \% \mathrm{~B}$ for the first $3 \mathrm{~min}$, followed by a linear increase to $80 \% \mathrm{~B}$ in $20 \mathrm{~min}$, and further to $90 \% \mathrm{~B}$ in $5 \mathrm{~min}$.

HPLC-ESI ${ }^{+}$-MS/MS analysis of tryptic peptides was performed using an Agilent 1100 capillary HPLCion trap MS system. Chromatographic separation was achieved using a Zorbax SB-C18 column $(150 \mathrm{~mm} \times 0.5 \mathrm{~mm}, 5 \mu \mathrm{m})$ eluted at a flow rate of $15 \mu \mathrm{L} / \mathrm{min}$. The mobile phase consisted of $0.5 \%$ formic acid $/ 0.01 \%$ TFA in water (A) and $0.5 \%$ formic acid $/ 0.01 \%$ TFA in acetonitrile (B). The solvent composition was held at $3 \% \mathrm{~B}$ for the first $3 \mathrm{~min}$, increased to $5 \% \mathrm{~B}$ over $7 \mathrm{~min}$, held at $5 \% \mathrm{~B}$ for $10 \mathrm{~min}$, increased to $35 \% \mathrm{~B}$ in $95 \mathrm{~min}$, and further to $75 \% \mathrm{~B}$ in 10 min. The mass spectrometer was operated in $\mathrm{ESI}^{+}$mode, and Auto $\mathrm{MS}^{2}$ was used to select and fragment the doubly-charged ions at $m / z 658.4$ (unmodified peptide $\mathrm{G}^{136}$ NPVPILIPCHR ${ }^{147}$ ), $\mathrm{m} / z$ 849.6 (chlorambucil-induced guanine cross-link to $\mathrm{G}^{136}$ NPVPILIPCHR ${ }^{147}$ ), $\mathrm{m} / z, 775.4$ (mechlorethamine-induced guanine cross-link to $\mathrm{G}^{136} \mathrm{NPVPILIPCHR}^{147}$ ), $\mathrm{m} / 2834.4$ (unmodified peptide $\mathrm{V}^{148}$ VCSSGAVGNYSGGLAVK ${ }^{165}$ ), $\mathrm{m} / 2$ 1025.9 (chlorambucil-induced guanine cross-link to $\mathrm{V}^{148} \mathrm{VCSSGAVGNYSGGLAVK}^{165}$ ), and $\mathrm{m} / \mathrm{z} 951.4$ (mechlorethamine-induced guanine cross-link to $\mathrm{V}^{148}$ VCSSGAVGNYSGGLAVK $^{165}$ ).

HPLC-ESI ${ }^{+}$-MS/MS analysis of amino acid-guanine cross-links present in total digests of alkylated proteins was performed using an Agilent 1100 capillary HPLC-ion trap MS system operated in $\mathrm{ESI}^{+}$mode. Auto $\mathrm{MS}^{2}$ was used to isolate and fragment the $[\mathrm{M}+\mathrm{H}]^{+}$ions of $N-$ (2-[S-cysteinyl] ethyl)- $N$-(2-[guan-7-yl] ethyl)- $p$-aminophenylbutyric acid (Cys-N7G-PBA, $m /$ $z$ 504.2), $N$-(2-[S-cysteinyl]ethyl)- $N$-(2-[guan-7-yl]ethyl)methylamine (Cys-N7G-EMA, $m / z$ 356.2 ), and the corresponding conjugates to arginine, tyrosine, lysine and histidine.

Chlorambucil-induced conjugates were separated using a Synergi C18 column $(250 \mathrm{~mm} \times 0.5$ $\mathrm{mm}, 4 \mu \mathrm{m}$ ) eluted at a flow rate of $10 \mu \mathrm{L} / \mathrm{min}$. The mobile phase consisted of $15 \mathrm{mM}$ ammonium acetate, $\mathrm{pH} 5.0$ in water (A) and acetonitrile (B), with a linear gradient of $2-65 \%$ B over the course of $30 \mathrm{~min}$ at $10^{\circ} \mathrm{C}$. For separation of mechlorethamine-induced amino acid-guanine, solvent composition was held at $2 \%$ B for $15 \mathrm{~min}$, followed by a linear increase to $30 \% \mathrm{~B}$ over the next $15 \mathrm{~min}$.

\section{Detection of Nitrogen Mustard-Induced AGT-DNA Cross-Links in Nuclear Protein Extracts}

Chinese hamster ovary cells expressing human recombinant AGT (CHO-AGT) and their wildtype/empty vector equivalent (CHO-EV) (10) were maintained as exponentially growing monolayer cultures in $\alpha$-MEM supplemented with $9 \%$ FBS and G418 $(1 \mathrm{mg} / \mathrm{mL})$ in a humidified incubator at $37^{\circ} \mathrm{C}$ with $5 \% \mathrm{CO}_{2}$. Nuclear protein extracts from both cell lines were prepared as previously described (11) and dialyzed overnight at $4^{\circ} \mathrm{C}$ against $10 \mathrm{mM}$ TRIS$\mathrm{HCl} / 10 \mathrm{mM} \mathrm{KCl} / 10 \mathrm{mM} \mathrm{MgCl} 2$ (pH 7.4) using Slide-A-Lyzer dialysis cassettes (3.5 kDa molecular weight cut-off) from Pierce (Rockford, IL). Protein concentrations were determined via colorimetric assay (12). 
5'-Biotinylated double-stranded oligodeoxynucleotides (5'-GGAGCTCGTGGCCTA-3' (+) strand, $3.12 \mathrm{nmol})$ were combined with the CHO-AGT nuclear extract $(0.5 \mathrm{mg})$ in $10 \mathrm{mM}$ TRIS- $\mathrm{HCl}-\mathrm{pH} 7.4$ in the absence and presence of mechlorethamine $(100,250,500,750$, and $1000 \mu \mathrm{M})$. The reaction mixtures were incubated at $37^{\circ} \mathrm{C}$ for $3 \mathrm{~h}$ to induce cross-linking. Biotinylated DNA with any bound proteins was captured on streptavidin sepharose high performance beads. The beads were washed with $0.1 \%$ SDS, $4 \mathrm{M}$ urea, and $1 \mathrm{M} \mathrm{NaCl}$ to remove any non-covalently attached proteins. Biotinylated DNA containing covalently bound proteins was released from the beads upon the addition of 4X SDS-PAGE loading buffer and heating to $90^{\circ} \mathrm{C}$ for $15 \mathrm{~min}$. DNA-protein cross-links present in the elutes were separated by 10 or $12 \%$ SDS-PAGE, and the presence of AGT was detected by both Western blotting and tandem mass spectrometry.

Immunological experiments employed commercial anti-MGMT, clone MT3.1 (1:500 dilution) and alkaline phosphatase-conjugated anti-mouse IgG (1:10,000 dilution). The amount of AGT present was determined by direct comparison of the band intensity to that of known AGT standards analyzed in parallel. Percent cross-linking was determined by dividing the amount of AGT present in the biotin capture by the total amount of AGT in the reaction mixture.

For mass spectrometric identification of cross-linked proteins, SDS-PAGE gels were stained with SimplyBlue SafeStain (Invitrogen, Carlsbad, CA) and sample lanes were cut into 10 slices comprising the entire molecular weight range. Upon further dicing of the gel pieces into $1 \mathrm{~mm}$ pieces and washing with $100 \mathrm{mM}$ ammonium bicarbonate, each fraction was subjected to reduction and alkylation with dithiothreitol and iodoacetaminde as previously described (13). Gel pieces were dehydrated with acetonitrile, dried under vacuum, and reconstituted in $25 \mathrm{mM}$ ammonium bicarbonate containing mass spectrometry grade trypsin $(\sim 1 \mu \mathrm{g})$. The samples were digested overnight at $37^{\circ} \mathrm{C}$. Tryptic peptides were extracted from the gel pieces using $0.1 \%$ aqueous formic acid $/ 60 \%$ acetonitrile, evaporated to dryness, and resuspended in $0.1 \%$ aqueous formic acid. HPLC-ESI ${ }^{+}$-MS/MS analyses were performed on a Thermo LTQ linear ion trap MS system equipped with a Thermo Surveyor solvent delivery system and a microelectrospray source. Tryptic peptides were resolved on a $100 \mu \mathrm{m} \times 11 \mathrm{~cm}$ fused silica capillary column packed with $5 \mu \mathrm{m}, 300 \AA ̊$ Jupiter $\mathrm{C} 18$ (Phenomenex, Torrence, CA) eluted at $0.6 \mu \mathrm{L} / \mathrm{min}$ with 0.1 formic acid in water (A) and $0.1 \%$ formic acid in acetonitrile (B). Solvent composition was kept at $2 \% \mathrm{~B}$ for the first $15 \mathrm{~min}$, followed by a linear increase to $25 \% \mathrm{~B}$ over the next $35 \mathrm{~min}$, and further to $90 \%$ B in the next $15 \mathrm{~min}$, and held at $90 \%$ B for $10 \mathrm{~min}$. MS/MS spectra of peptides were acquired using data-dependent scanning in which a single full MS spectrum (400-2000 m/z) was followed by four MS/MS spectra. Spectra were recorded using dynamic exclusion of previously analyzed precursors for $60 \mathrm{~s}$. The MS/MS spectra were searched against human and Cricetulus griseus (Chinese hamster) database sequences using the SEQUEST algorithm (14). $S$-Carboxamidomethylation at cysteine ( $+57 \mathrm{Da})$, oxidation of methionine $(+16$ $\mathrm{Da}$ ), and mechlorethamine-induced alkylation at cysteine (hydrolyzed monoadduct: $+102 \mathrm{Da}$, guanine cross-link: $+234 \mathrm{Da}$ ) were specified as dynamic modifications to identify spectra of adducted peptides.

\section{Results}

\section{SDS PAGE Detection of Nitrogen Mustard-Induced AGT-DNA Cross-Links}

To examine the ability of nitrogen mustards to cross-link AGT protein to DNA, recombinant human AGT and 5'-32 P-end labeled DNA duplexes were incubated in the presence of increasing amounts of mechlorethamine or chlorambucil, followed by SDS-PAGE analysis. The results presented in Figure 1 reveal that a slow-migrating species corresponding to an AGT-DNA conjugate was formed when duplex DNA was exposed to nitrogen mustard drugs in the presence of AGT. No such product was formed in control experiments in which either AGT or oligonucleotide was omitted. Cross-linking of AGT to DNA by mechlorethamine displayed 
concentration-dependence, with increasing amounts of drug resulting in 15 to $25 \%$ of recombinant protein being cross-linked to DNA (lanes 3-5). Chlorambucil was less effective at cross-linking AGT to DNA (relative amount of AGT cross-linked by drug: 2-5\%, lanes 810). Additional low-mobility bands were observed following treatment of AGT DNA mixtures with high concentrations of nitrogen mustards. These appear to represent higher-order complexes of AGT and DNA. In contrast, no conjugates were observed following similar treatment of Histone H4 (Supporting Information S-2).

\section{Mass Spectrometry Analysis of Half Mustard-Induced AGT-Guanine Cross-Links: Whole Protein Results}

Initial DNA alkylation by mechlorethamine and chlorambucil leads to the formation of N7guanine half mustards, which retain one of the chloroethyl groups (Scheme 1). These monoadducts can then react with a nucleophilic site within a neighboring protein, giving rise to DNA-protein cross-links. To gain insight into the nature of the nitrogen mustard-induced AGT-DNA linkages, recombinant AGT protein or its variants were incubated with synthetic guanine half mustards of mechlorethamine or chlorambucil as models of monoalkylated DNA, followed by capillary HPLC-ESI ${ }^{+}$-MS analysis of modified proteins (Scheme 2). When the experiment was performed with the wild type protein, deconvoluted mass spectra of the reaction mixture revealed three protein species: unreacted AGT $(M=21880 \mathrm{Da})$, AGT containing a single chlorambucil crosslink to guanine $(M=22263 \mathrm{Da})$, and a double chlorambucil cross-link to guanine $(M=22646 \mathrm{Da})$ (Fig. 2A). The presence of a large molar excess of L-cysteine (100-500 equivalents) did not inhibit alkylation of AGT by N7G-PBA$\mathrm{Cl}$, suggesting that this low molecular weight thiol does not protect against the formation of DNA-protein cross-links upon exposure to nitrogen mustards (data not shown). These results were consistent with a previous study in which $\mathrm{L}$-cysteine and glutathione did not prevent the formation of DEB-mediated AGT-DNA cross-links (6).

When the same experiment was conducted with a variant form of AGT in which cysteine 145 was replaced by an alanine residue, a single half mustard-modified species was apparent $(M=$ 23401 , mass increase of $\sim 384 \mathrm{Da}$ ) (Figure 2B), suggesting that one of the cross-linking sites observed within the wild-type protein, namely Cys ${ }^{145}$, had been removed. Incubation of a third variant of AGT protein in which cysteine residues 145 and 150 had both been mutated (C145A/ $\mathrm{C} 150 \mathrm{~S}$ ) with chlorambucil half mustard yielded only trace amounts of cross-linked protein (Figure 2C). The significant differences between the observed molecular weights of the C145A and C145A/C150S AGT variants ( $M=23017 \mathrm{Da}$ and $M=23001 \mathrm{Da})$ and the wild type protein $(M=21880)$ are due to the presence of an N-terminal histidine tag (MRGSHHHHHHGS).

Similar results were obtained following reaction of wild type AGT with the guanine half mustard of mechlorethamine (Figure 2D), with both single ( $M=22110 \mathrm{Da})$ and double $(M=$ $22345 \mathrm{Da}$ ) cross-links to guanine observed. A third species of alkylated AGT was also identified ( $M=21959 \mathrm{Da}$ ), corresponding to a mechlorethamine-induced intramolecular crosslink involving two amino acid residues within the protein. Taken together, these results support the interpretation that chlorambucil and mechlorethamine cross-link AGT to DNA via cysteine residues 145 and 150 . In contrast, no alkylation of histone $\mathrm{H} 4$ was observed following exposure to N7G-PBA-Cl or N7G-EMA-Cl (Supporting Information S-3 and S4).

\section{Capillary HPLC-ESI+-MS/MS Analysis of Half Mustard-Induced AGT-Guanine Cross-Links: Peptide Mapping}

Further evidence for nitrogen mustard-mediated cross-linking of AGT to DNA via the two active site cysteines within the protein was obtained through MS/MS sequencing of peptides resulting from proteolytic digestion of alkylated AGT. HPLC-ESI ${ }^{+}$-MS/MS analysis of a tryptic digest of N7G-PBA-Cl-treated AGT detected a prominent doubly-charged ion at 850.1 
$m / z$ corresponding to a drug-induced conjugate involving peptide $\mathrm{G}^{136} \mathrm{NPVPILIPCHR}^{147}$ and a guanine base (calculated $M=1697.8 \mathrm{Da}$ ). The MS/MS spectrum (Figure 3A) was consistent with the presence of a chlorambucil-guanine adduct located at either Cys ${ }^{145}$ or His ${ }^{146}$. While the masses of product ions $b_{3}-b_{8}$ were in agreement with the theoretical values for the unmodified peptide, the mass of $b_{11}$ was increased by $383 \mathrm{Da}$ (observed $M=1523.2 \mathrm{Da}$ versus calculated $M=1140.5 \mathrm{Da}$ for the unmodified peptide). The $y_{4}-y_{9}$ ions also contained the chlorambucil-guanine cross-link as indicated by the 383 Da mass shift. $\mathrm{MS}^{3}$ analysis of the $y_{8}{ }^{*}$ fragment ion $\left(\mathrm{P}^{140}\right.$ ILIPCHR $^{147}, \mathrm{~m} / z 1331.0[\mathrm{M}+\mathrm{H}]^{+}$) yielded product ions corresponding to $b_{6}, b_{7}, y_{5}$, and $y_{4}+383 \mathrm{Da}$, mapping the site of modification to Cys ${ }^{145}$ (Figure 3B). Further proof of modification at Cys ${ }^{145}$ was obtained upon analysis of synthetic peptide

GNPVPILIPCHR containing a chlorambucil cross-link to guanine $\left(m / z 849.7[\mathrm{M}+2 \mathrm{H}]^{2+}\right)$ which displayed similar HPLC retention time and MS/MS fragmentation as the AGT-derived peptide-guanine cross-link (Supporting Information S-5). The second cross-linking site was similarly identified at $\mathrm{Cys}^{150}$ by $\mathrm{MS}^{2}$ sequencing of the peptide $\mathrm{V}^{148}$ VCSSGGAVGNYSGGLAVK ${ }^{165}$ (calculated $M=2049.8 \mathrm{Da}$, with $\underline{\mathrm{C}}$ corresponding to the chlorambucil-guanine conjugate of Cys (Supporting Information S-6). Analogous results were obtained upon analysis of tryptic fragments resulting from proteolytic digestion of N7GEMA-Cl-treated AGT (Supporting Information S-7 and S-8). In neither series of experiments were other peptides found to contain guanine half mustard-induced lesions, suggesting that nitrogen mustard-mediated cross-linking of AGT to DNA occurs only via cysteines 145 and 150 of the protein.

To confirm this interpretation, additional experiments were performed in which recombinant AGT protein was incubated with nitrogen mustard drugs in the presence of double-stranded DNA (Scheme 2). Analysis of tryptic digests detected alkylation of the same two cysteine residues - Cys ${ }^{145}$ and Cys ${ }^{150}$ - suggesting that they are inherently reactive towards nitrogen mustard-derived aziridinium ions (Supporting Information S-9 and S-10). In addition, treatment of AGT with mechlorethamine in the presence of DNA produced an intramolecular AGT cross-link involving cysteines 145 and 150 according to MS/MS sequencing of tryptic peptides (Supporting Information S-11).

\section{Capillary HPLC-ESI ${ }^{+}$-MS/MS Analysis of AGT Total Digests}

To establish the exact molecular structures of AGT-DNA conjugates, N7G-PBA-Cl and N7GEMA-Cl treated AGT proteins were subjected to complete hydrolysis, followed by capillary HPLC-ESI ${ }^{+}$-MS/MS analysis of the resulting amino acids (Figure 4). Synthetic cysteineguanine conjugates, $N$-(2-[S-cysteinyl]ethyl)- $N$-(2-[guan-7-yl]ethyl)- $p$-aminophenylbuyric acid (Cys-N7G-PBA) and $N$-(2-[S-cysteinyl]ethyl)- $N$-(2-[guan-7-yl]ethyl)methylamine (CysN7G-EMA), were used as authentic standards. HPLC-ESI ${ }^{+}$-MS/MS analysis of AGT digests following exposure to N7G-PBA-Cl detected a prominent peak at $\mathrm{m} / \mathrm{z}, 504.2$ which had the same retention time, MS/MS fragmentation pattern, and UV spectrum as Cys-N7G-PBA (Figure 4). In contrast, no HPLC-ESI ${ }^{+}$-MS/MS signals were observed in the ion channels corresponding to chlorambucil-induced guanine conjugates to other nucleophilic residues (Lys, Arg, His, Tyr). Similar results were observed for N7G-EMA-Cl (Supporting Information S-12). These data establish the covalent structures of amino acid-nucleobase conjugates induced by chlorambucil and mechlorethamine as Cys-N7G-PBA and Cys-N7G-EMA, respectively.

\section{AGT-DNA Cross-Linking in the Presence of Other Cellular Proteins}

To determine whether AGT-DNA cross-linking can occur in the presence of other cellular proteins, an affinity based approach was developed (Scheme 3). Nuclear protein extracts were prepared from transgenic Chinese hamster ovary $(\mathrm{CHO})$ cells that express recombinant human AGT (10) and from Chinese hamster ovary cells transfected with an empty vector which does not express human AGT. These extracts were incubated with synthetic DNA duplexes 
containing a 5' biotin tag (5'-GGAGCTGGTGGCGTAGGC-3', (+) strand) in the presence and absence of mechlorethamine. Streptavidin beads were then employed to capture any proteins chemically cross-linked to the biotinylated DNA. Following stringent washing procedures to remove any non-covalently bound proteins, biotinylated DNA along with any covalently attached proteins was eluted with SDS-PAGE loading buffer, and the resulting proteins were analyzed by Western blotting and HPLC-ESI ${ }^{+}$-MS/MS of tryptic digests.

Immunological detection with anti-MGMT antibody revealed the concentration-dependent formation of drug-induced AGT-DNA cross-links in nuclear protein extracts from the AGTexpressing $\mathrm{CHO}$ cell line (Figure 5, lanes 2-6). Cross-linking of AGT to DNA increased from $\sim 2.0 \%$ to $10.0 \%$ as the mechlorethamine concentration increased from 100 to $1000 \mu \mathrm{M}$ based upon signal comparison to known AGT standards. Very little AGT was detected in the biotin capture of reactions lacking mechlorethamine (Figure 5, lane 1), DNA, or AGT (data not shown).

Identification of AGT protein from biotin capture experiments was further confirmed by mass spectrometry of tryptic digests. Protein mixtures were separated by SDS-PAGE, and the proteins were subjected to in-gel tryptic digestion prior to HPLC-ESI ${ }^{+}$-MS/MS. Upon analysis of peptides present in the biotin capture of mechlorethamine-treated samples, three distinct AGT tryptic peptides were identified: $F^{108}$ GEVISYQQLAALAGNPK ${ }^{125}$, $\mathrm{V}^{148}$ VCSSGAVGNYSGGLAVK $^{165}$, and L $^{176}$ GKPGLGGSSGLAGAWLK $^{193}$ (see example in Figure 6). In contrast, no AGT peptides were detected in the biotin capture from the control reaction lacking mechlorethamine. Taken together, our results support the formation of AGTDNA cross-links in the presence of other cellular proteins.

\section{Discussion}

Historically, DNA-protein cross-links have received less attention than other DNA lesions. As a result, the biological consequences and cellular mechanisms for the repair of these lesions are not fully understood. As bulky, helix-distorting lesions, DNA-protein cross-links can block the binding and progression of protein complexes, potentially interfering with crucial cellular processes including DNA replication, transcription, DNA repair, recombination, and chromatin remodeling (4). The formation of DNA-protein cross-links can occur upon exposure to a variety of cytotoxic, mutagenic, and carcinogenic agents, including ionizing radiation (15), metals (4), endogenous and exogenous aldehydes (16), and chemotherapeutic drugs $(17 ; 18)$. Because certain types of DNA-protein cross-links have been shown to persist through several cycles of DNA replication due to lack of repair (4), DNA-protein cross-linking could play an important role in the cytotoxic activity of many antitumor drugs traditionally known for cross-linking DNA, including the nitrogen mustards.

We present the first evidence for the cross-linking of a specific DNA repair protein, $O^{6}$ alkylguanine DNA alkyltransferese, to DNA in the presence of antitumor nitrogen mustards. Denaturing gel electrophoresis detected a concentration-dependent formation of AGT-DNA conjugates following incubation of human recombinant AGT protein with ${ }^{32} \mathrm{P}$-labeled oligonucleotides in the presence of nitrogen mustards (Figure 1). Mass spectrometry analysis of recombinant human AGT that had been incubated with guanine half mustards as models for monoalkylated DNA confirmed these findings and revealed that cross-linking can take place at two different sites within the protein (Figures 2A and 2D). Mutagenesis studies indicated that the two observed cross-linking sites reside at the active site cysteine residues, Cys ${ }^{145}$ and Cys ${ }^{150}$, since their replacement with Ala and Ser, respectively, blocked cross-linking (Figures $2 \mathrm{~B}$ and $2 \mathrm{C}$ ). These results were fully supported by HPLCESI ${ }^{+}$-MS/MS sequencing of tryptic peptides obtained from AGT treated with guanine half mustards (Figure 3and Supporting Information S-6 through S-8) or mustards in the presence of double stranded DNA (Supporting 
Information S-9 and S-10). The exact structures of the cross-links were established as $N$-[2[S-cysteinyl]ethyl]- $N$-[2-(guan-7-yl)ethyl]methylamine and $N$-(2-[S-cysteinyl]ethyl)- $N$-(2[guan-7-yl]ethyl)-p-aminophenylbuyric acid for mechlorethamine and chlorambucil, respectively, based on HPLC-ESI ${ }^{+}$-MS/MS analysis of amino acidnucleobase conjugates in total protein digests in comparison with the corresponding synthetic standards (Figure 4 and Supporting Information S-12).

In comparing the overall cross-linking ability of the two nitrogen mustards used in this study, several interesting observations were made. For reactions in which cross-linking was initiated between double-stranded oligodeoxynucleotides and AGT via the addition of free drug, mechlorethamine displayed a greater cross-linking efficiency (Figure 1). This is not surprising since nitrogen mustard drugs, including chlorambucil, were specifically designed to afford compounds with reduced reactivity/toxicity for chemotherapeutic applications (19). However, reactions in which cross-linking was achieved upon incubation of AGT with synthetic guanine half mustards, chlorambucil appeared to be a more efficient cross-linker (Figure 2). This may be explained by a higher affinity of N7G-PBA-Cl with its aromatic substituent for the primarily hydrophobic active site pocket of AGT (20).

Using a novel biotin/streptavidin enrichment strategy in combination with immunodetection and tandem mass spectrometry, AGT-DNA cross-linking in the presence of other cellular proteins was established. Upon incubation of 5'-biotinylated oligonucleotides with nuclear proteins from AGT-expressing CHO cells (in which AGT comprises 0.5\% of total protein), AGT-DNA cross-linking displayed concentration dependence, with cross-link amounts increasing from 2 to $10 \%$ as the mechlorethamine concentration increased from 100-1000 $\mu \mathrm{M}$ (Figure 5). Similar results were obtained in HeLa nuclear extracts, a cell line with endogenous expression of AGT (Loeber and Tretyakova, unpublished results). Although these studies employed a large excess of mechlorethamine to afford levels of cross-linking detectable by Western blotting/HPLC-ESI+-MS/MS, these results may still hold biological relevance as DNA-protein cross-links would likely cause significant disruption to normal cellular processes, including DNA replication and transcription.

Our results support nitrogen mustard-induced AGT-DNA cross-linking involving two active site cysteine residues (Cys ${ }^{145}$ and $\mathrm{Cys}^{150}$ ), despite the presence of three other cysteine residues within the protein. These same two sites were also modified when the recombinant protein was treated with chlorambucil or mechlorethamine in the absence of DNA (Supporting Information S-13 through S-18), suggesting selective reactivity of these residues towards nitrogen mustards. These results are consistent with our previous results for AGT-DNA cross-linking by diepoxybutane (6).

To gain further insight into the specificity of AGT in forming DNA-protein cross-links, similar experiments were conducted with another DNA-binding protein, histone H4. Upon SDSPAGE analysis of reaction mixtures in which histone $\mathrm{H} 4$ had been incubated with both nitrogen mustards in the presence of ${ }^{32} \mathrm{P}$-end labeled oligodeoxynucleotides, no histone-DNA crosslinks were observed (Supporting Information S-2). Likewise, ESI ${ }^{+}$-MS analysis of histone $\mathrm{H} 4$ treated with N7G-PBA-Cl or N7G-EMA-Cl yielded the same deconvoluted MS spectra (Supporting Information S-3 and S-4), suggesting that no cross-linking had taken place. Upon total digestion of half mustard-treated histone $\mathrm{H} 4$ to amino acids, no amino acid-guanine conjugates were detected (data not shown). These negative results were consistent with a previous study that showed that no DNA-histone cross-linking had occurred following treatment of nuclear protein extracts with mechlorethamine (21). Unlike AGT, histone H4 contains no cysteines. Instead, it contains numerous nucleophillic lysine and arginine residues. The apparent lack of nitrogen mustard-induced histone-DNA cross-linking may be attributed 
to the fact that the side chains of lysine and arginine are protonated at physiological $\mathrm{pH}$, thus preventing attack by the positively charged aziridinium ions (Scheme 1).

As nitrogen mustard-mediated DNA-protein cross-linking displays selectivity for AGT, questions are raised regarding the role of this important repair protein in the cellular response to bifunctional alkylating agents. Within the cell, AGT is responsible for the irreversible transfer of promutagenic $O^{6}$-alkylguanine lesions in DNA to an active site cysteine residue, $\mathrm{Cys}^{145}$, restoring normal guanine and preventing mutagenesis. Levels of AGT expression are highly variable between different tissues and tumor types, opening the possibility that it may mediate the biological effects of DNA alkylating drugs. Previous studies have yielded conflicting reports on the possible role of AGT in mediating cytotoxicity of nitrogen mustards, specifically cyclophosphamide and chlorambucil. Several papers provide evidence that AGT partially protects against the toxicity and mutagenicity of cyclophosphamide metabolites and imparts resistance to treatment of tumor xenografts (22). In CHO cells, expression of human AGT was found to protect against the toxic and mutagenic effects of cyclophosphamide, and that the metabolite acrolein was responsible for generating the lesions in which AGT afforded protection (23). Although the idea that AGT may be acting as a molecular scavenger was proposed, a more recent study has shown that DNA binding is required for AGT-mediated protection against acrolein toxicity, suggesting that the active site thiol is not simply sequestering this reactive metabolite (24). However, in other studies in cultured cells, survival was not affected by AGT activity (25), and a comparison of the therapeutic response of 23 tumor xenografts showed no correlation with AGT levels (26). The presence of AGT renders E. coli strains more sensitive to killing by chlorambucil (27) but no effect of AGT status on drug sensitivity was seen in a studies of HeLa or CHO cells (25). Clinical studies have also yielded conflicting results on the role of AGT levels in the outcome of therapy with cyclophosphamide [reviewed (24)]. Recently, it was shown that MGMT does not protect against mutations induced by cyclophosphamide in mice (28).

The present results showing that AGT can be cross-linked to DNA by nitrogen mustards adds another factor that must be considered in the overall effect of AGT levels to the response to treatment. This cross-linking could increase the toxicity, and the extent to which this is balanced or exceeded by the ability to repair other adducts may determine the overall biological response.

\section{Supplementary Material}

Refer to Web version on PubMed Central for supplementary material.

\section{Abbreviations}

Cys-N7G-EMA

Cys-N7G-PBA

N7G-EMA-Cl

N7G-PBA-Cl

$O^{6}$-alkylguanine DNA

alkyltransferase
$N$-[2-[S-cysteinyl]ethyl]- $N$-[2-(guan-7-yl)ethyl] methylamine

$N$-(2-[Scysteinyl] ethyl)- $N$-(2-[guan-7-yl]ethyl)- $p$ aminophenylbuyric acid

$N$-(2-chloroethyl)- $N$-[2-(guan-7-yl)ethyl]methylamine

$N$-(2-chloroethyl)- $N$-[2-(guan-7-yl)ethyl]-p-

aminophenylbutyric acid

AGT 


\section{Acknowledgments}

We thank Kris Murphy, Danae Quirk Dorr, Vallabha Tantry, Melissa Goggin, and Zhou Xin (University of Minnesota Cancer Center) for synthesizing guanine half mustards and guanine-amino acid conjugates of nitrogen mustards; Brock Matter (University of Minnesota Cancer Center), Simona Codreanu and Daniel Liebler (Mass Spectrometry Research Center, Vanderbilt University) for help with mass spectrometry experiments, and Bob Carlson (University of Minnesota Cancer Center) for preparing figures for this manuscript. Funding for this research was from Leukemia Research Foundation and the National Cancer Institute grants to N.T. (R01-CA-100670) and A.P. (R01-CA-018137). R.L. was partially supported by the NIH Chemistry-Biology Interface Training Grant (T32-GM08700) and the University of Minnesota Cancer Center.

\section{Reference List}

1. Lawley PD, Brookes P. Molecular mechanism of the cytotoxic action of difunctional alkylating agents and of resistance to this action. Nature 1965;206(983):480-483. [PubMed: 5319105]

2. Osborne MR, Lawley PD. Alkylation of DNA by melphalan with special reference to adenine derivatives and adenine-guanine cross-linking. Chem. Biol. Interact 1993;89(1):49-60. [PubMed: 8221966]

3. Liu L, Hachey DL, Valadez G, Williams KM, Guengerich FP, Loktionova NA, Kanugula S, Pegg AE. Characterization of a mutagenic DNA adduct formed from 1,2-dibromoethane by $O^{6}$-alkylguanineDNA alkyltransferase. J. Biol. Chem 2004;279(6):4250-4259. [PubMed: 14645247]

4. Barker S, Weinfeld M, Murray D. DNA-protein crosslinks: their induction, repair, and biological consequences. Mutat. Res 2005;589(2):111-135. [PubMed: 15795165]

5. Valadez JG, Liu L, Loktionova NA, Pegg AE, Guengerich FP. Activation of bis-electrophiles to mutagenic conjugates by human $O^{6}$-alkylguanine-DNA alkyltransferase. Chem. Res. Toxicol 2004;17 (7):972-982. [PubMed: 15257623]

6. Loeber R, Rajesh M, Fang Q, Pegg AE, Tretyakova N. Cross-linking of the human DNA repair protein $O^{6}$-alkylguanine DNA alkyltransferase to DNA in the presence of 1,2,3,4-diepoxybutane. Chem. Res. Toxicol 2006;19(5):645-654. [PubMed: 16696566]

7. Pegg AE. Repair of $O^{6}$-alkylguanine by alkyltransferases. Mutat. Res 2000;462(2-3):83-100. [PubMed: 10767620]

8. Liu L, Xu-Welliver M, Kanugula S, Pegg AE. Inactivation and degradation of $O^{6}$-alkylguanine-DNA alkyltransferase after reaction with nitric oxide. Cancer Res 2002;62(11):3037-3043. [PubMed: 12036910]

9. Edara S, Kanugula S, Goodtzova K, Pegg AE. Resistance of the human $O^{6}$-alkylguanine-DNA alkyltransferase containing arginine at codon 160 to inactivation by $O^{6}$-benzylguanine. Cancer Res 1996;56(24):5571-5575. [PubMed: 8971155]

10. Cai Y, Wu MH, Xu-Welliver M, Pegg AE, Ludeman SM, Dolan ME. Effect of $O^{6}$-benzylguanine on alkylating agent-induced toxicity and mutagenicity in Chinese hamster ovary cells expressing wild-type and mutant $O^{6}$-alkylguanine-DNA alkyltransferases. Cancer Res 2000;60(19):5464-5469. [PubMed: 11034089]

11. Jessberger R, Berg P. Repair of deletions and double-strand gaps by homologous recombination in a mammalian in vitro system. Mol. Cell Biol 1991;11(1):445-457. [PubMed: 1986239]

12. Bradford MM. A rapid and sensitive method for the quantitation of microgram quantities of protein utilizing the principle of protein-dye binding. Anal. Biochem 1976;72(1-2):248-257. [PubMed: 942051]

13. Shin NY, Liu Q, Stamer SL, Liebler DC. Protein targets of reactive electrophiles in human liver microsomes. Chem. Res. Toxicol 2007;20(6):859-867. [PubMed: 17480101]

14. Eng JK, McCormack AL, Yates JR. An approach to correlate tandem mass spectral data of peptides with amino acid sequences in a protein database. J. Am. Soc. Mass Spectrom 1994;5(11):976-989.

15. Barker S, Weinfeld M, Zheng J, Li L, Murray D. Identification of mammalian proteins cross-linked to DNA by ionizing radiation. J. Biol. Chem 2005;280(40):33826-33838. [PubMed: 16093242]

16. Murata-Kamiya N, Kamiya H. Methylglyoxal, an endogenous aldehyde, crosslinks DNA polymerase and the substrate DNA. Nucleic Acids Res 2001;29(16):3433-3438. [PubMed: 11504881] 
17. Ewig RA, Kohn KW. DNA damage and repair in mouse leukemia L1210 cells treated with nitrogen mustard, 1,3-bis(2-chloroethyl)-1-nitrosourea, and other nitrosoureas. Cancer Res 1977;37(7 Pt 1): 2114-2122. [PubMed: 558823]

18. Kloster M, Kostrhunova H, Zaludova R, Malina J, Kasparkova J, Brabec V, Farrell N. Trifunctional dinuclear platinum complexes as DNA-protein cross-linking agent. Biochemistry 2004;43(24):77767786. [PubMed: 15196020]

19. Mutschler, E.; Derendorf, H., editors. Chemotherapy of Malignant Tumors. Drug Actions: Basic Principles and Therapeutic Aspects. Stuttgart: Medpharm Scientific Publishers; 1995. p. 600-601.

20. Daniels DS, Woo TT, Luu KX, Noll DM, Clarke ND, Pegg AE, Tainer JA. DNA binding and nucleotide flipping by the human DNA repair protein AGT. Nat. Struct. Mol. Biol 2004;11(8):714720. [PubMed: 15221026]

21. Berger SL. Histone modifications in transcriptional regulation. Curr. Opin. Genet. Dev 2002;12(2): 142-148. [PubMed: 11893486]

22. Friedman HS, Pegg AE, Johnson SP, Loktionova NA, Dolan ME, Modrich P, Moschel RC, Struck R, Brent TP, Ludeman S, Bullock N, Kilborn C, Keir S, Dong Q, Bigner DD, Colvin OM. Modulation of cyclophosphamide activity by $O^{6}$-alkylguanine-DNA alkyltransferase. Cancer Chemother. Pharmacol 1999;43(1):80-85. [PubMed: 9923545]

23. Cai Y, Wu MH, Ludeman SM, Grdina DJ, Dolan ME. Role of $O^{6}$-alkylguanine-DNA alkyltransferase in protecting against cyclophosphamide-induced toxicity and mutagenicity 1 . Cancer Res 1999;59 (13):3059-3063. [PubMed: 10397244]

24. Hansen RJ, Ludeman SM, Pegg AE, Dolan ME. Role of MGMT in protecting against cyclophosphamide-Induced toxicity in cells and animals. DNA Repair 2007;6:1145-1154. [PubMed: 17485251]

25. Preuss I, Thust R, Kaina B. Protective effect of $O^{6}$-methylguanine-DNA methyltransferase (MGMT) on the cytotoxic and recombinogenic activity of different antineoplastic drugs. Int. J. Cancer 1996;65 (4):506-512. [PubMed: 8621235]

26. D'Incalci M, Bonfanti M, Pifferi A, Mascellani E, Tagliabue G, Berger D, Fiebig HH. EORTC SPG and PAMM Groups. The antitumour activity of alkylating agents is not correlated with the levels of glutathione, glutathione transferase and $O^{6}$-alkylguanine-DNA-alkyltransferase of human tumour xenografts. Eur. J. Cancer 1998;34(11):1749-1755. [PubMed: 9893664]

27. Salmelin C, Hovinen J, Vilpo J. Polymyxin permeabilization as a tool to investigate cytotoxicity of therapeutic aromatic alkylators in DNA repair-deficient Escherichia coli strains. Mutat. Res 2000;467 (2):129-138. [PubMed: 10838200]

28. Hansen RJ, Nagasubramanian R, Delaney SM, Samson LD, Dolan ME. Role of $O^{6}$-methylguanineDNA methyltransferase in protecting from alkylating agent-induced toxicity and mutations in mice. Carcinogenesis 2007;28(5):1111-1116. [PubMed: 17116724] 


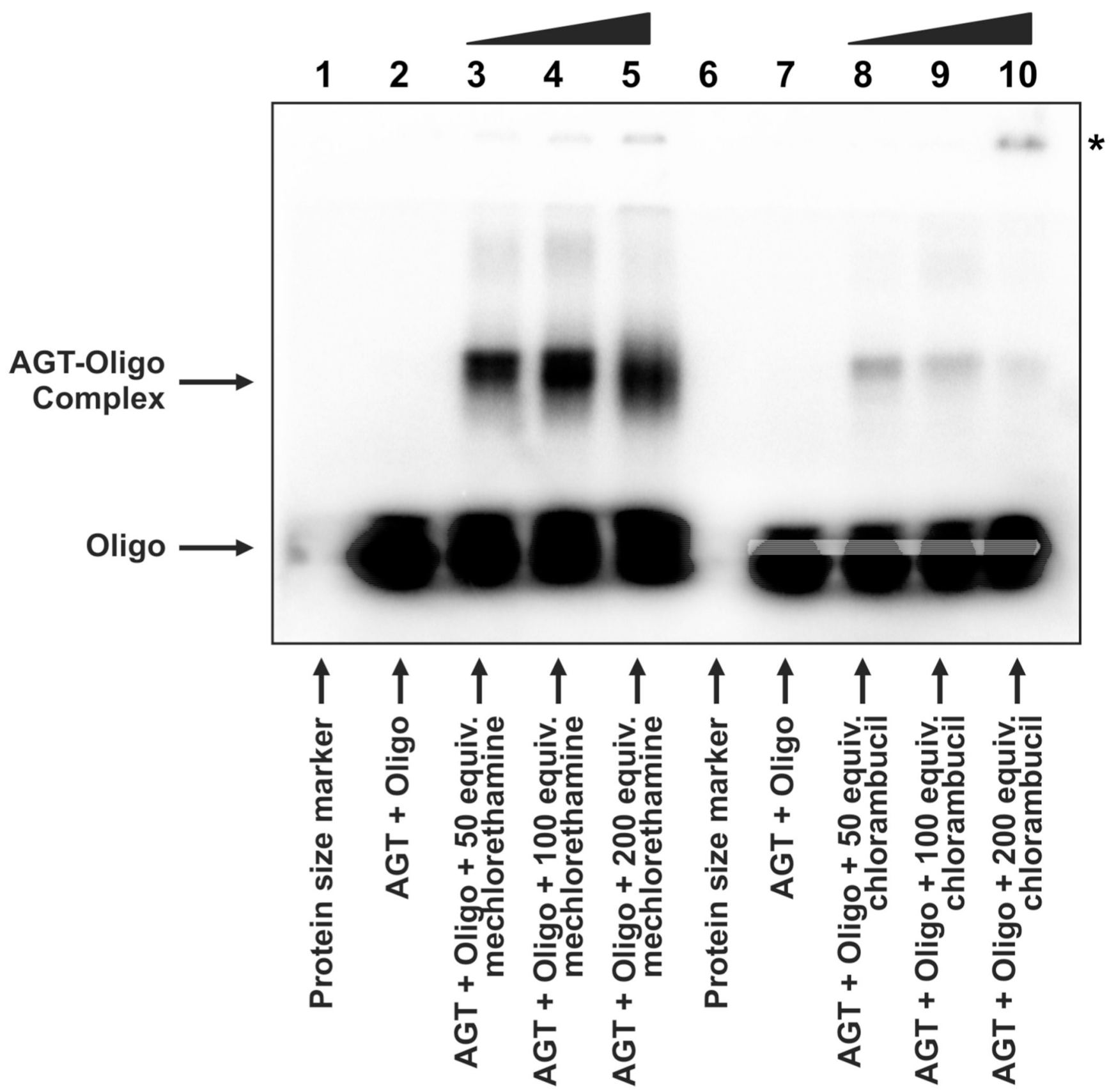

Figure 1.

Detection of drug-induced AGT-DNA cross-links. Recombinant human AGT protein and radioactive duplex oligodeoxynucleotide (see Materials and Methods) were incubated in the presence of 50 (lanes 3 and 8), 100 (lanes 4 and 9) or 200 (lanes 5 and 10) equivalents of mechlorethamine (lanes 3-5) or chlorambucil (lanes 8-10) and subsequently resolved by $12 \%$ SDS-PAGE. Free duplex DNA (labeled 'Oligo') migrated to the bottom of the gel, whereas DNA cross-linked to AGT (labeled 'AGT-Oligo complex') displayed a substantially reduced mobility. The mobility of the higher-order complex of drug and AGT is indicated by an asterisk (see text). 

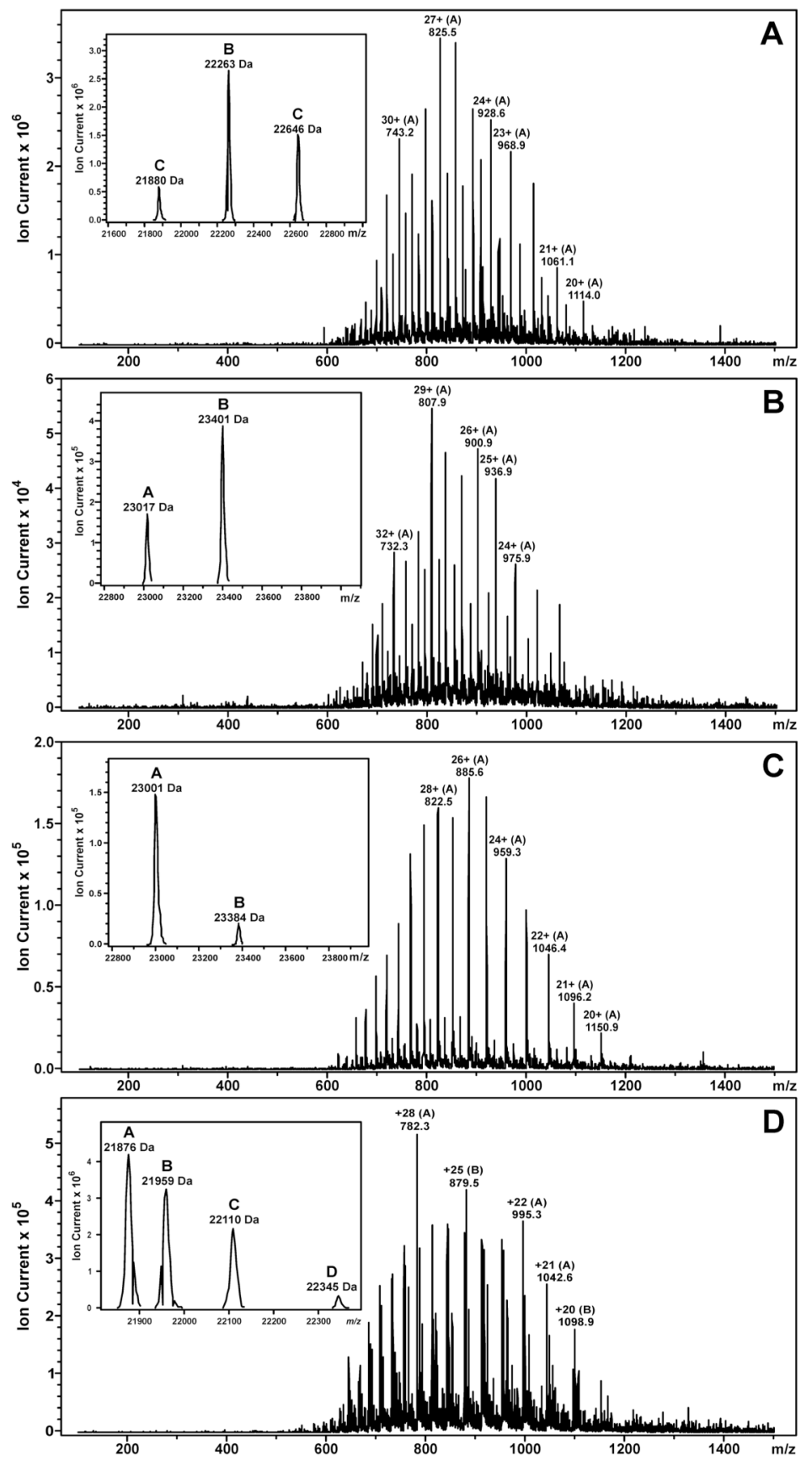

Figure 2.

$\mathrm{ESI}^{+}$-MS spectra and deconvoluted spectra (inset) of N7G-PBA-Cl and N7G-EMA-Cl treated AGT protein and its variants. (A) Wild type protein: $A=$ unmodified AGT (calculated $M=21$ $876 \mathrm{Da}$, observed $M=21880 \mathrm{Da}$ ), $B=$ AGT containing a single chlorambucil cross-link to guanine (calculated $M=22259 \mathrm{Da}$, observed $M=22263 \mathrm{Da}$ ), $C=$ AGT containing two chlorambucil cross-links to guanine (calculated $M=22642 \mathrm{Da}$, observed $M=22646 \mathrm{Da}$ ). (B) C145A AGT variant: $A=$ unmodified C145A AGT (calculated $M=23015 \mathrm{Da}$, observed $M=23017 \mathrm{Da}$ ), $B=\mathrm{C} 145 \mathrm{~A}$ AGT containing a single chlorambucil cross-link to guanine (calculated $M=23398 \mathrm{Da}$, observed $M=23401 \mathrm{Da}$ ). (C) C145A/C150S variant: $A=$ unmodified C145A/C150S AGT (calculated $M=22996$ Da, observed $M=23001 \mathrm{Da}$ ), $B=$ 
C145A/C150S AGT containing a single chlorambucil cross-link to guanine (calculated $M=$ $23379 \mathrm{Da}$, observed $M=23384 \mathrm{Da}$ ). (D) Wild type protein: $A=$ unmodified AGT (calculated $M=21876 \mathrm{Da}$, observed $M=21876 \mathrm{Da}$ ), $B=$ AGT containing an intramolecular mechlorethamine cross-link (calculated $M=21959 \mathrm{Da}$, observed $M=21959 \mathrm{Da}$ ), $C=$ AGT containing a single mechlorethamine cross-link to guanine (calculated $M=22110 \mathrm{Da}$, observed $M=22110 \mathrm{Da}$ ), $D=$ AGT containing two mechlorethamine cross-links to guanine (calculated $M=22344 \mathrm{Da}$, observed $M=22345 \mathrm{Da}$ ). 
A
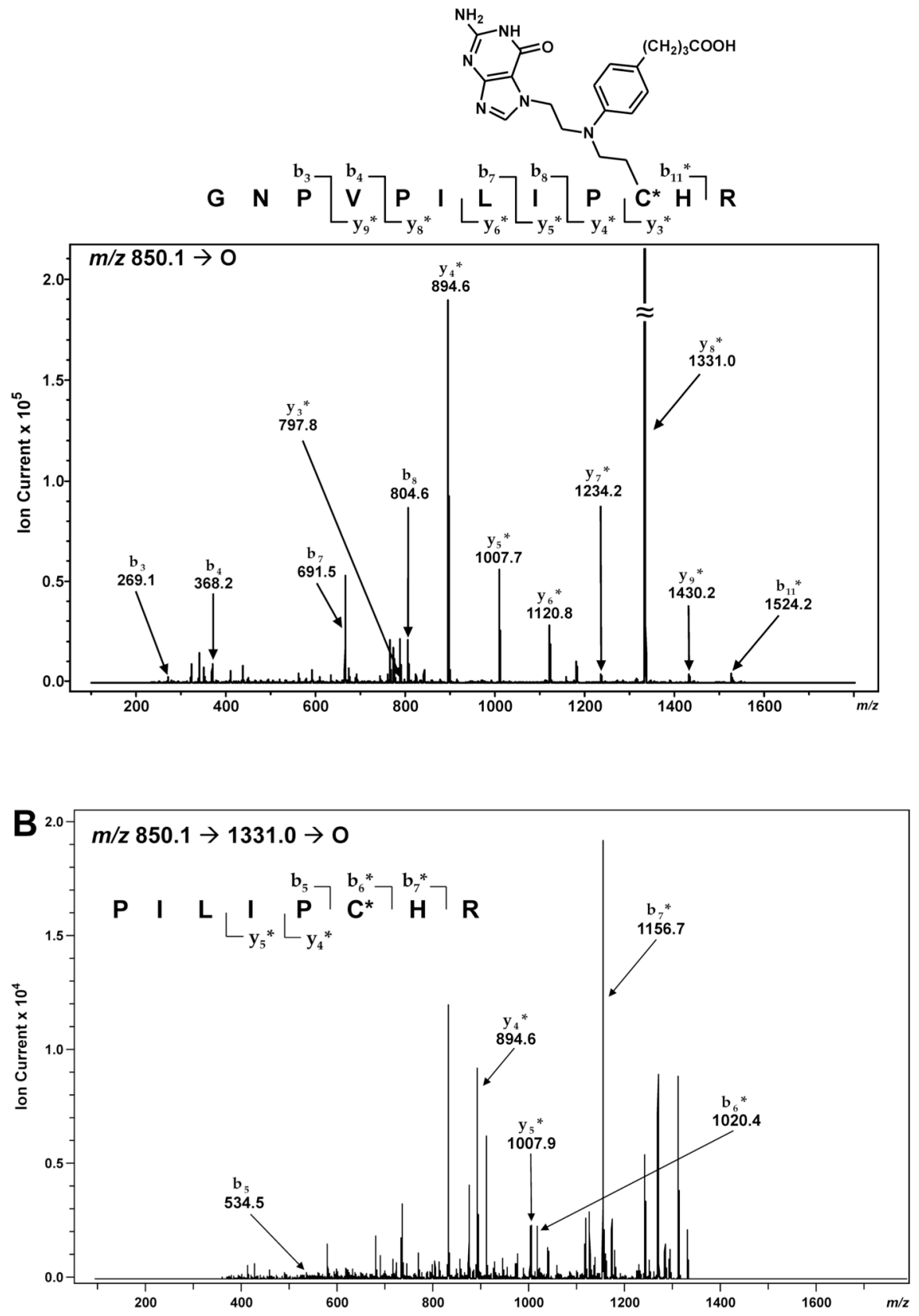

Figure 3.

MS/MS (A) and $\mathrm{MS}^{3}$ spectrum (B) of the AGT tryptic peptide $\mathrm{G}^{136}$ NPVPILIPCHR $^{147}$ containing chlorambucil-guanine cross-link at $\underline{\mathrm{C}}\left(\mathrm{Cys}^{145}\right)$. 

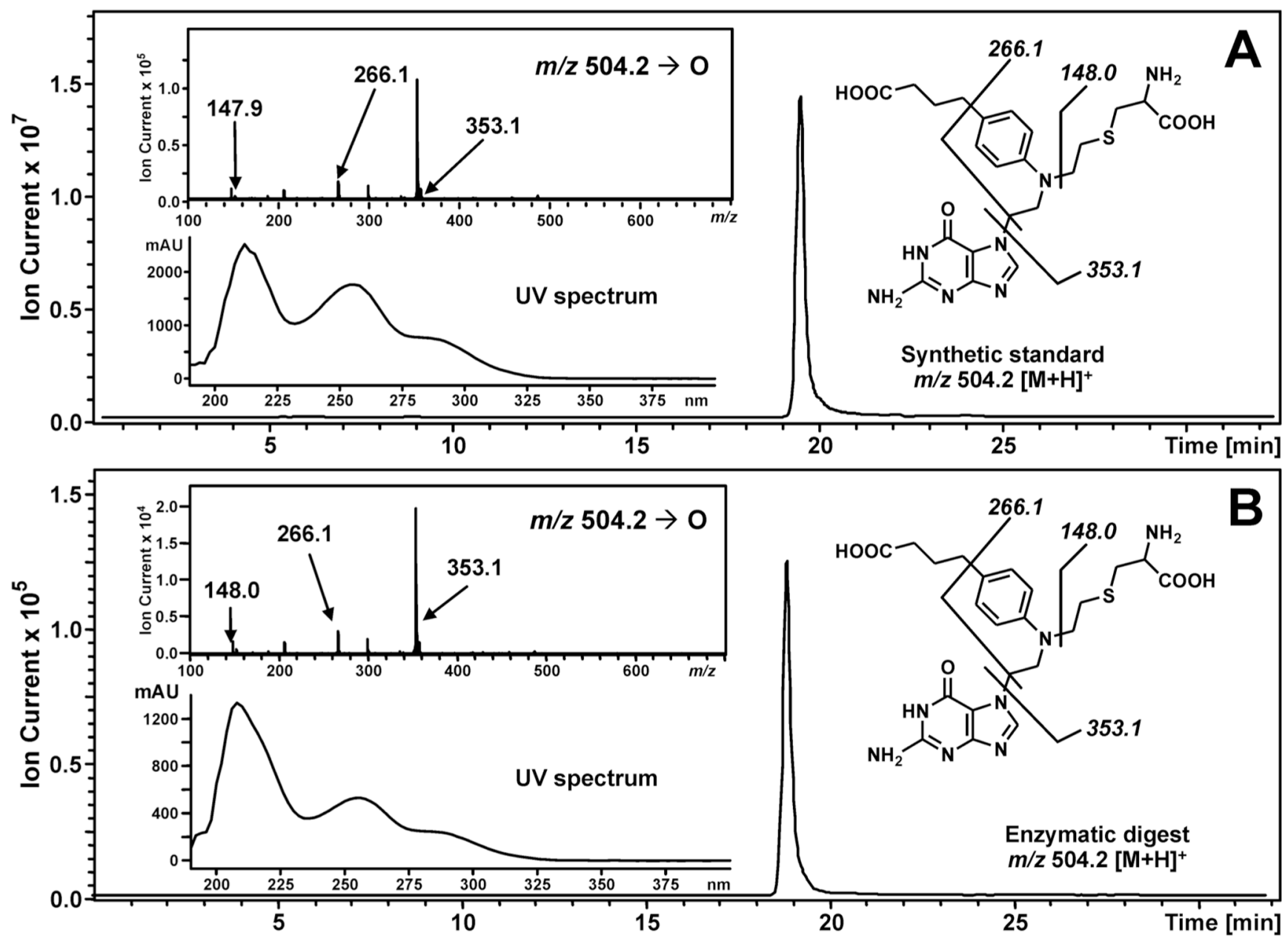

Figure 4.

HPLC-ESI ${ }^{+}$MS/MS analysis of amino acid-guanine conjugates of chlorambucil. (A) Extracted ion chromatogram of synthetic Cys-N7G-PBA $\left(\mathrm{m} / z 356.2[\mathrm{M}+\mathrm{H}]^{+}\right)$; Inset: MS/MS fragmentation and UV spectrum. (B) Extracted ion chromatogram of AGT-derived Cys-N7GPBA $\left(m / z\right.$ 356.2 $[\mathrm{M}+\mathrm{H}]^{+}$; Inset: MS/MS fragmentation and UV spectrum. 


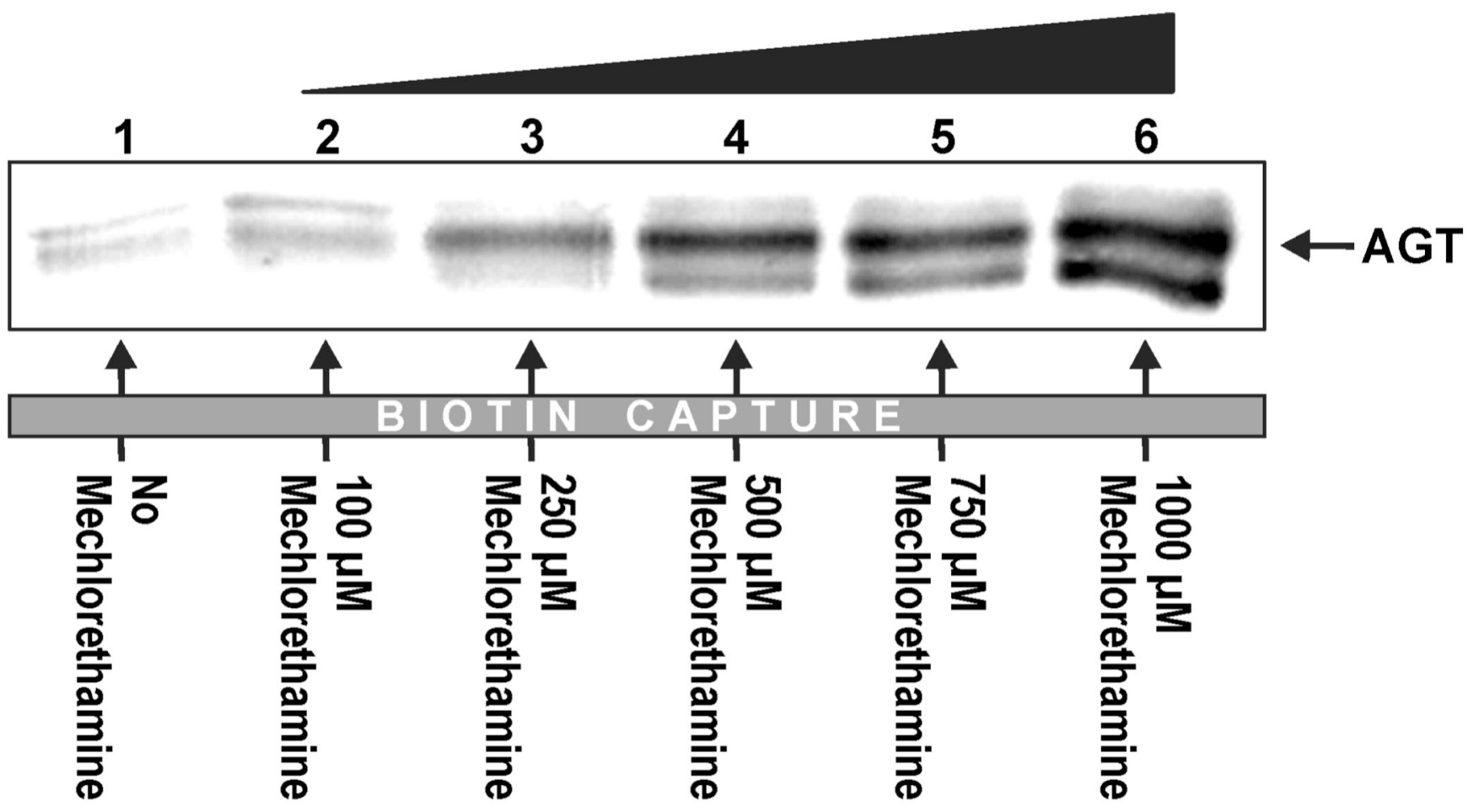

Figure 5.

Mechlorethamine induces AGT-DNA cross-links in nuclear protein extracts as indicated by Biotin capture assay. Biotinylated double-stranded oligodeoxynucleotides (5'-

GGAGCTCGTGGCCTA-3' (+) strand, $3.12 \mathrm{nmol}$ ) were incubated with nuclear protein extracts from Chinese hamster ovary cells (CHO) expressing human AGT in the absence (lane 1) or presence of increasing amounts of mechlorethamine (lanes 2-6). Botinylated DNA and AGT-DNA cross-links were captured using streptavidin sepharose high performance beads, washed with buffers containing SDS, urea, and $\mathrm{NaCl}$ to remove non-covalently bound proteins, and eluted via heating in SDS-PAGE loading buffer. The presence of AGT in the biotin capture fractions following DNA elution was detected by Western blot analysis using a monoclonal antibody against AGT. 


\begin{tabular}{crrrr}
\hline Seq & $\boldsymbol{\#}$ & \multicolumn{1}{c}{$\mathbf{b}$} & \multicolumn{1}{c}{$\mathbf{y}$} & \\
\hline $\mathrm{F}$ & 1 & 148.1 & 1906.0 & 18 \\
$\mathrm{G}$ & 2 & 205.1 & 1758.9 & 17 \\
$\mathrm{E}$ & 3 & $\mathbf{3 3 4 . 1}$ & 1701.9 & 16 \\
$\mathrm{~V}$ & $\mathbf{4}$ & $\mathbf{4 3 3 . 2}$ & 1572.9 & 15 \\
$\mathrm{I}$ & 5 & $\mathbf{5 4 6 . 3}$ & $\mathbf{1 4 7 3 . 8}$ & 14 \\
$\mathrm{~S}$ & 6 & $\mathbf{6 3 3 . 3}$ & $\mathbf{1 3 6 0 . 7}$ & 13 \\
$\mathrm{Y}$ & 7 & $\mathbf{7 9 6 . 4}$ & $\mathbf{1 2 7 3 . 7}$ & 12 \\
$\mathrm{Q}$ & 8 & $\mathbf{9 2 4 . 4}$ & $\mathbf{1 1 1 0 . 6}$ & 11 \\
$\mathrm{Q}$ & 9 & $\mathbf{1 0 5 2 . 5}$ & $\mathbf{9 8 2 . 6}$ & 10 \\
$\mathrm{~L}$ & 10 & $\mathbf{1 1 6 5 . 6}$ & $\mathbf{8 5 4 . 5}$ & 9 \\
$\mathrm{~A}$ & 11 & $\mathbf{1 2 3 6 . 6}$ & $\mathbf{7 4 1 . 4}$ & 8 \\
$\mathrm{~A}$ & 12 & $\mathbf{1 3 0 7 . 7}$ & $\mathbf{6 7 0 . 4}$ & 7 \\
$\mathrm{~L}$ & 13 & $\mathbf{1 4 2 0 . 7}$ & $\mathbf{5 9 9 . 4}$ & 6 \\
$\mathrm{~A}$ & 14 & $\mathbf{1 4 9 1 . 8}$ & $\mathbf{4 8 6 . 3}$ & 5 \\
$\mathrm{G}$ & 15 & $\mathbf{1 5 4 8 . 8}$ & $\mathbf{4 1 5 . 2}$ & 4 \\
$\mathrm{~N}$ & 16 & $\mathbf{1 6 6 2 . 8}$ & $\mathbf{3 5 8 . 2}$ & 3 \\
$\mathrm{P}$ & 17 & 1759.9 & $\mathbf{2 4 4 . 2}$ & 2 \\
$\mathrm{~K}$ & 18 & 1888.0 & 147.1 & 1 \\
\hline
\end{tabular}

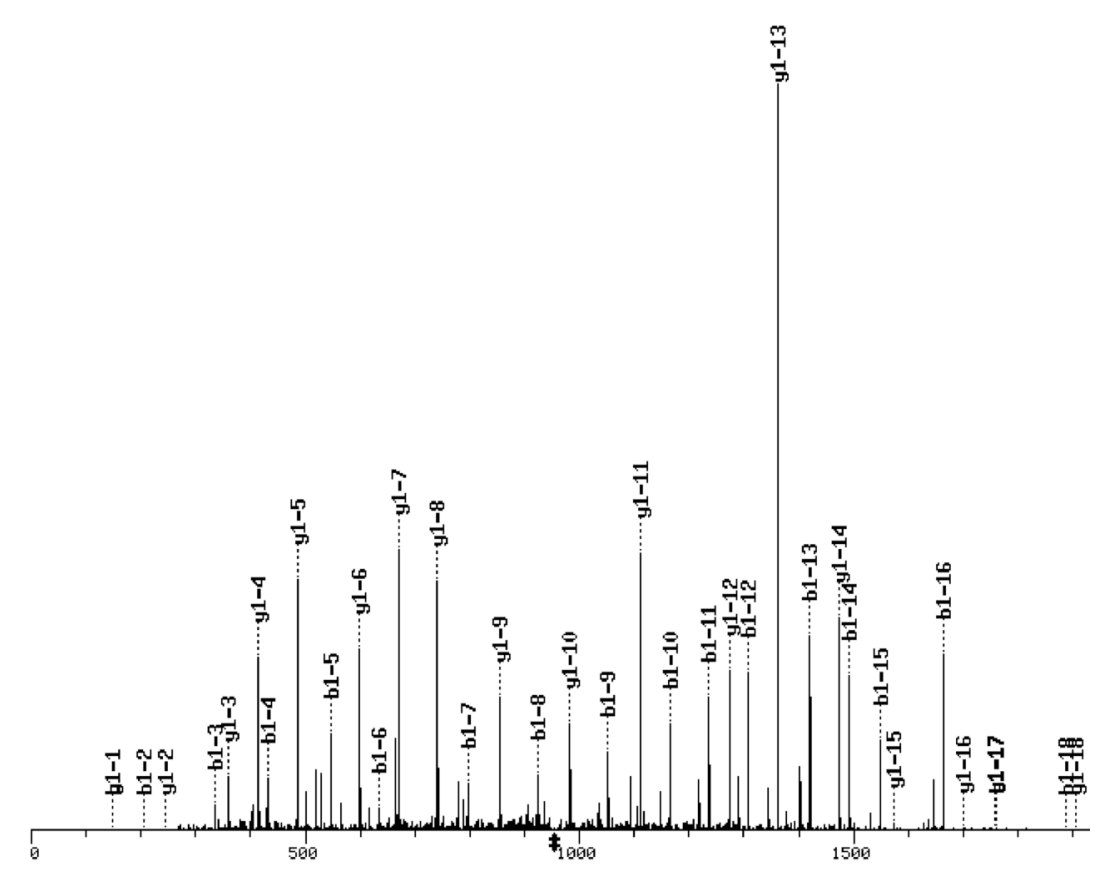

Figure 6.

HPLC-ESI ${ }^{+}$-MS/MS identification of AGT tryptic peptide $\mathrm{F}^{108}$ GEVISYQQLAALAGNPK ${ }^{125}$ resulting from biotin capture of AGT-DNA cross-links. 
<smiles>[R]N(CCCl)CCN([R])CCn1cnc2nc(N)[nH]c(=O)c21</smiles>

Nitrogen Mustard

Aziridinium Ion
Guanine Half Mustard
$\mathrm{R}=\mathrm{CH}_{3}$, mechlorethamine

$\mathrm{R}=-\left(\mathrm{CH}_{2}\right)_{3} \mathrm{COOH}, \mathrm{chlorambucil}$
$\mathrm{R}=\mathrm{CH}_{3}, \mathrm{~N} 7 \mathrm{G}-\mathrm{EMA}-\mathrm{CI}$

$R=-\left(\mathrm{CH}_{2}\right)_{3} \mathrm{COOH}, \mathrm{N} 7 \mathrm{G}-\mathrm{PBA}-\mathrm{Cl}$

Scheme 1.

Chemical structures of nitrogen mustards and guanine half mustards employed in this work. 


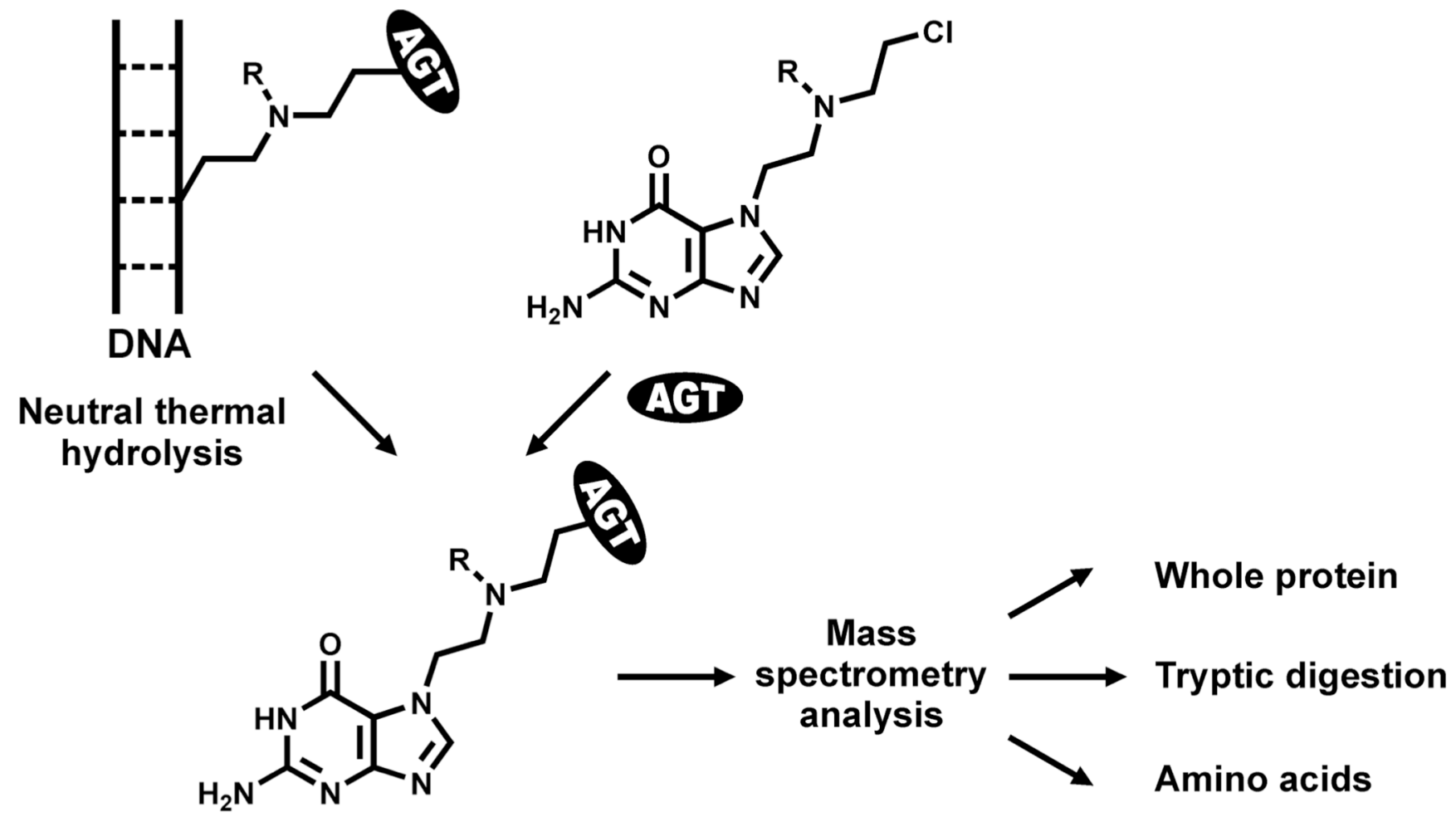

Scheme 2.

Mass Spectrometry-based approach used to characterize AGT-DNA cross-links of antitumor nitrogen mustards. 


\section{BIOTIN}
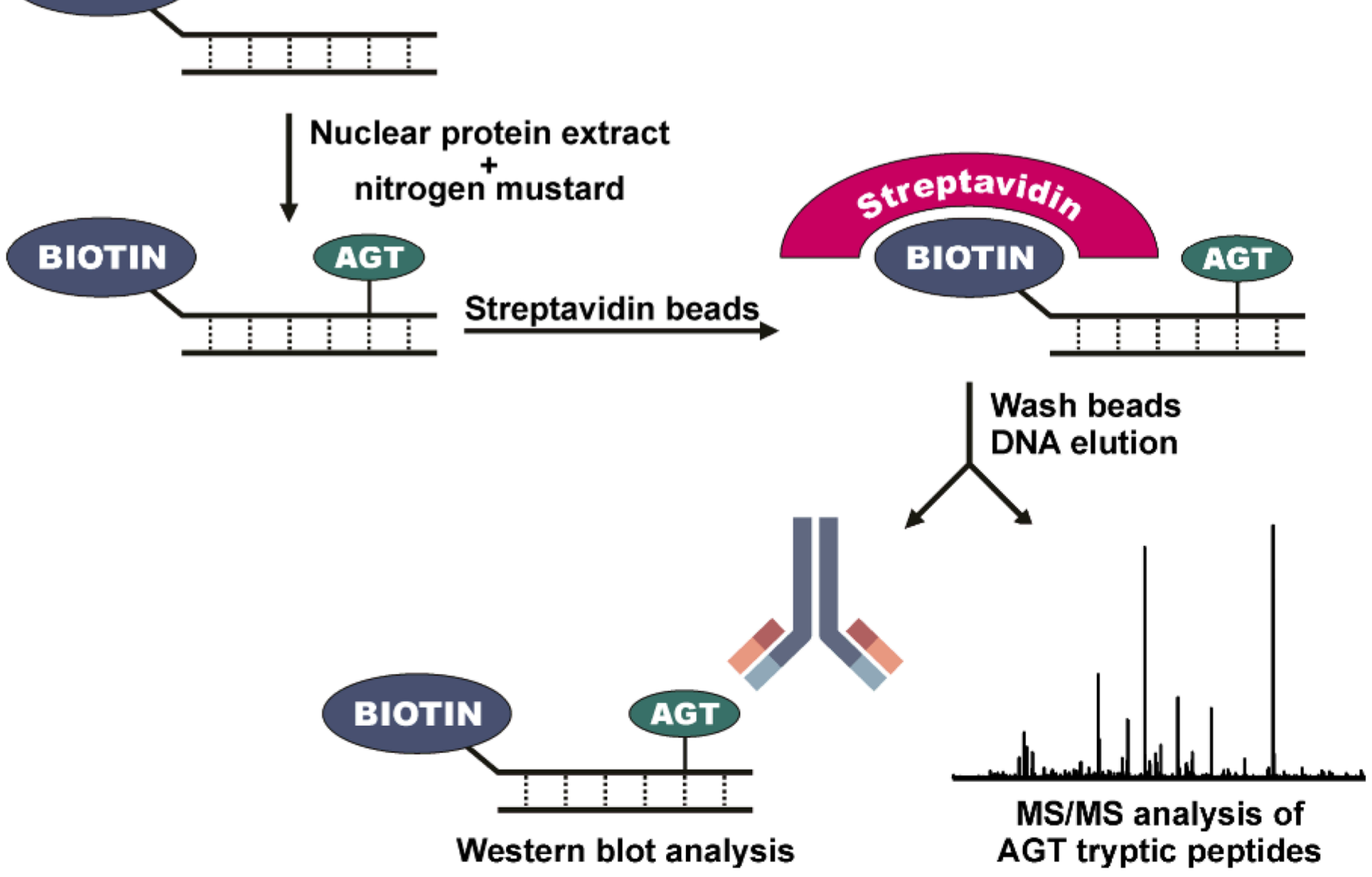

Scheme 3.

Biotin capture assay for AGT-DNA cross-links. 